\title{
Léxico de termos da indústria de plásticos
}

\section{PRINCIPAIS TIPOS DE MATÉRIA-PRIMA DA INDÚSTRIA TRANSFORMADORA DE PLÁS- TICOS}

1.1 Polímeros - Compostos macromoleculares. As macromoléculas são constituídas por longas sequências de unidades estruturais mais pequenas (monómeros), ligadas entre si por ligaçðes covalentes, resultantes de reacçð̃es ditas "de polimerização".

1.2 Homopolímeros - Polímeros resultantes da reacção de polimerização de moléculas iguais (um só monómero).

1.3 Copolímeros - Polimeros resultantes da reacção de polimerização a partir de moléculas diferentes (dois ou mais monómeros).

1.4 Misturas de polímeros - Matérias-primas resultantes da mistura de dois ou mais polimeros:

1.5 Resinas - Nome habitualmente dado aos polimeros enquanto matérias-primas da indústria transformadora.

1.6 Plásticos - Por vezes sinónimo de polímeros ou resinas. Normalmente significa polímeros já aditivados.

1.7 Termoplásticos - Polímeros que podem ser "fundidos" e "solidificados" sucessivas vezes sem perda muito significativa das suas propriedades fundamentais. A sua transformação é, pois, reversível.

1.8 Termoendurecíveis - Polímeros que, uma vez aquecidos ou produzidos em molde, adquirem uma forma permanente. A sua transformação é não reversível.

1.9 Elastómeros - Polímeros que sob a acção de uma tensão, se deformam significativamente, mas em que esta deformação é reversível.

1.10 Aditivos - Substâncias que se incorporam nos polimeros a fim de lhes conferir propriedades específicas.

1.11 Pigmentos e corantes - Aditivos destinados a conferir côr aos produtos plásticos.

1.12 Cargas - Aditivos destinados especificamente a aumentar a resistência mecânica dos produtos ou peças fabricadas.

1.13 Master-batch - Polímeros com uma aditivação superconcentrada, destinados a ser misturados com polímeros sem aditivação, por forma a obter misturas com a concentração desejável de aditivos.

1.14 Compound - Polimeros contendo já a incorporação de todos os aditivos, pigmentos e cargas desejados nos produtos transformados.
1.15 Grãos ou "Pellets" - Forma sob a qual são habitualmente apresentados os polimeros. Estes tomam o aspecto de grânulos tipo bago de arroz e são obtidos por extrusão a partir de pó.

1.16. Pos - É a forma em que geralmente se apresentam os polimeros, como resultado directo das reacçð̄es de polimerização. Por vezes são comercializados sob esta forma.

2. TECNOLOGIAS DE TRANSFORMAÇÃO "Transformação" ou "processamento" dos polímeros consiste na obtenção de artigos ou peças plásticas, a partir das respectivas matérias-primas.

2.1 Extrusão - E o processo de transformação mais utilizado. Transforma a matéria-prima, em grãos (“pellets") ou em pó, fundindo-a e fazendo-a passar através de uma fieira com a configuração adequada. Efectua-se em máquinas designadas por "extrusoras". A plastificação ou "fusão" do polímero é feita pela acção conjugada da compressão por um parafuso sem fim e do aquecimento por uma- camisa circundante. Em certos casos este aquecimento usa-se apenas para iniciar o processo, pois a energia necessária para o continuar provém unicamente da pressão exercida pelo sem fim. Estas extrusoras designam-se por "adiabáticas".

2.1.1 Extrusão de filme plano - Extrusão em que a fieira tem uma forma rectangular com uma das dimensð̋es muito pequena, não só em valor absoluto (p. ex. $1 \mathrm{~mm}$ ) mas também quando comparada com a outra (alguns centímetros a vários metros). $O$ extrudido é estirado na direcção da extrusão com a consequente redução de espessura.

2.1.2 Extrusão de filme tubular - Extrusão em que a fieira é também filiforme, mas em forma de circunferência. $O$ plástico sai da fieira com a forma de tubo, no eixo do qual é soprado ar. Origina-se assim um novo tubo de parede muito mais fina (designado por "balão") e de diâmetro consideravelmente superior. O balão é planificado e estirado no sentido da extrusão. O balão corre sempre verticalmente tanto no sentido ascendente como descendente e é, normalmente, arrefecido pelo ar da sala ou nave em que a extrusora está instalada. Para se obterem filmes de polipropileno (PP) de alta transparência usa-se-uma extrusão descendente em que o balão é arrefecido por anel de água fria.

2.1.2.1 Extrusão de rafia - É uma extrusão cuja 1.a parte é igual à do filme plano ou do filme tubular, mas em que o filme é cortado por uma série de lâminas em

a Companhia Nacional de Petroquímica. 
tiras muito finas e posteriormente sujeitas a um novo estiramente em banho de ar (estufa) ou de água. Após este estiramento fazem-se novelos. Por tecelagem obtêm-se produtos diversos (sacos para cereais, etc...).

2.1.2.2 Extrusão de monofilamento - É uma extrusão em que se utiliza uma multifieira.

2.1.3 Extrusão placa - Extrusão idêntica à do filme plano, mas com uma maior espessura do extrudido, em que a força de "puxo" (tracção) não provoca estiramento sensível. $O$ extrudido mantém, assim, aproximadamente a mesma espessura que à saída da fieira (em geral $1 \mathrm{~mm}$ a $1 \mathrm{~cm}$ ).

2.1.4 Extrusão tubo - Extrusão semelhante à extrusão placa quanto à espessura do extrudido, mas em forma de circunferência.

2.1.5 Extrusão perfil - Semelhante à extrusão placa ou tubo mas com outra qualquer forma.

2.1.6 Co-extrusão - Termo habitualmente aplicado à extrusão concêntrica de vários filmes tubulares (dois ou três), em geral de matérias-primas diferentes, que após a saida das respectivas fieiras são soldados uns aos outros quando da formação do balão.

2.2 Extrusão sopro - Parte de uma extrusão semelhante à extrusão tubo, na posição vertical descendente, mas em que um molde móvel, dividido em duas partes, vem envolver o tubo. Dá-se então uma insuflação de ar, em posição axial, que expande o material contra o molde. Também já se pratica co-extrusão sopro.

2.3 Laminagem - Contracolagem de filmes planos ou placas.

2.4 Compressão ou prensagem - Prensagem do material entre os pratos aquecidos de uma prensa.

2.5 Injecção - Processo de transformação em que o material é "fundido" ou plastificado como numa extrusora, mas posteriormente injectado para dentro de um molde, tomando a forma deste. A injecção é provocada não pela compressão do sem fim, mas pela força resultante da deslocação longitudinal deste.

2.6 Termo-formação - Trata-se de um processo em que após uma extrusão placa, antes da solidificação esta é comprimida contra um molde (por vácuo ou ar comprimido), tomando a respectiva forma.

2.7 R.I.M. - Esta tecnologia de transformação (Reaction Internal Molding), que significa "reacção no interior do molde", aplica-se quando o processo de polimerização ocorre dentro do próprio molde. Por exemplo no caso do poliuretano, os seus dois componentes principais (poliol e poliisocianato), líquidos à temperatura ambiente, são misturados no exterior do molde e "vazados" para o seu interior, antes de ocorrer a polimerização.

3. ENSAIOS DE IDENTIFICAÇÃO DE POLÍMEROS E PLÁSTICOS - Os ensaios a seguir referidos não são, regra geral, normalizados.

3.1 Espectrofotometria no infra-vermelho $-O$ espectro de absorção no I.V. é típico de cada variedade de polímeros. No entanto não permite distinguir entre polímeros da mesma família (por exemplo dois polietilenos de baixa densidade diferentes), nem entre uma mistura de dois ou mais polimeros e um copolímero dos mesmos polímeros, nem entre um copolímero aleatório (random) ou bloco (block).
3.2 N.M.R. (espectrometria de ressonância magnética nuclear) - Esta técnica analítica permite diferenciar um copolímero aleatório de um copolímero bloco.

3.3 G.P.C. e S.E.C. (cromatografia por permeação de gel e cromatografia por exclusão de tamanhos) - Técnicas cromatográficas variantes da cromatografia líquida de alta pressão e de alta temperatura (HTHPLC), que permitem determinar a distribuição de pesos moleculares de um polímero e daí deduzir os seus pesos moleculares médios típicos (p. ex. em número Mn e em peso $\mathrm{Mw}$ ) e o respectivo índice de heterogeneidade

$$
\alpha=\frac{M n}{M w}
$$

3.4 Outras técnicas - Não já para identificar os polímeros propriamente ditos, mas todos os outros componentes, voluntários ou involuntários dos plásticos (aditivos, corantes, cargas, restos de monómero, restos de catalizador, etc.), usam-se todas as técnicas habituais de análise, como sejam cromatografia líquida, gasosa, ou em camada fina, espectrofotometria visível e ultra-violeta, de absorção atómica, de fluorescência de Raios X, etc., muitas vezes sobre extractos do plástico em solventes adequados.

4. ENSAIOS DE CARACTERIZAÇÃO DAS MATÉRIAS-PRIMAS POLIMÉRICAS OU PLÁSTICAS Trata-se da medida de certas propriedades físicas das matérias-primas utilizadas na indústria transformadora para obtenção de objectos plásticos. Estas propriedades ditam o comportamento dos polímeros durante e após a transformação e portanto a sua adequação a cada fim particular.

Alguns ensaios de caracterização dos polímeros são feitos directamente sobre o conteúdo dos respectivos contentores (isto é sobre o pó ou grãos). Outros executam-se sobre provetes obtidos destes por um dos processos de transformação já referidos. Este ponto é particularmente importante, dado que o tipo de transformação utilizado confere propriedades específicas ao provete. Assim, os resultados obtidos para a mesma matéria-prima podem ser bastante diversos, consoante os provetes se obtiveram por prensagem a quente, extrusão ou injecção.

Estes ensaios são, regra geral, normalizados e constam dos manuais A.S.T.M., B.S., AFNOR, D.I.N., J.S.I.S.O., N.P., etc. Também é frequente constarem de manuais dos proprios produtores, com as mesmas ou outras designaçð̄es e com descriçðes por vezes iguais ou semelhantes.

As definiçōes que a seguir se apresentam não pretendem ter rigor científico, mas apenas dar um esclarecimento ou informação sobre cada ensaio.

4.1 Índice de fluidez (Melt Index) - É a propriedade mais importante dos termoplásticos, que condiciona o tipo de transformação que lhe é adequada. Consiste numa espécie de medida de viscosidade, com a diferença de que o produto "fundido"' a uma certa temperatura numa câmara, é obrigado a sair por um orificio situado na sua parte inferior, por pressão de um êmbolo sujeito a uma carga constante. É medida pela quantidade de produto extrudido em dez minutos, nas condiçðes do ensaio. O seu valor obtém-se por extrapolação. $\mathrm{O}$ ensaio dura habitualmente entre alguns segundos e seis minutos, mas a sụa preparação exige meia a uma hora.

4.2 Densidade - É uma propriedade de extrema importância para alguns polimeros, nomeadamente polie- 
tilenos de baixa e alta densidades (PEBD e PEAD). Pode-se medir pelos métodos clássicos, mas os mais habituais na indústria produtora são o da suspensão num líquido homogéneo cuja densidade se vai fazendo variar e o da suspensão na coluna de gradiente de densidades. Este método, extremamente simples é também extremamente preciso, permitindo obter densidades com quatro algarismos significativos.

A densidade de um plástico é muito influenciada pela respectiva aditivação. Também é muito influenciada pela história térmica do polímero, pelo que a sua determinação correcta pressupðe um recozimento prévio em condiçðes padronizadas.

\subsection{N.N.I. (Índice não Newtoniano-non Newtonian In-} dex) - Trata-se da medida do modo como o comportamento de um polimero fundido se afasta do de um líquido Newtoniano. $\mathrm{O}$ procedimento é algo semelhante ao do índice de fluidez, com a diferença de que, aqui, a velocidade do embolo é constante. O N.N.I. deduz-se a pastro da relação velocidade de extrusão-resistência à extrusão para duas velocidades diferentes do embolo.

Esta medida apresenta interesse prático, p. ex. no caso do PEAD em que é possível correlacionar o seu valor com o tipo de distribuição dos pesos moleculares (largo, médio, estreito).

4.4 Resistência à fissuração - Destina-se a medir a resistência dos plásticos à agressão por determinados meios, principalmente tensio-activos. Existem vários ensaios padrão para efectuar esta determinação, das quais o mais habitual é o ESCR (Environmental Stress Cracking Resistance).

4.5 Ponto Vicat - Mede a temperatura à qual se dá uma penetração determinada, num provete colocado num banho cuja temperatura se faz subir regularmente $\left(0,5\right.$ a $1^{\circ} \mathrm{C} /$ minuto), por um cone que suporta uma determinada carga.

4.6 Ponto H.D.T. (Heat Distortion Temperature) Ensaio realizado em condiçōes experimentais análogas às do ponto Vicat (normalmente utiliza-se um banho comum), mas em que, em vez de penetração, se provoca uma flexão de uma barra duplamente apoiada, causada por uma carga determinada.

4.7 Tracção, flexão, compressão - Conjunto de parâmetros medidos com uma máquina de tracção universal, sobre provetes normalizados. No caso da tracção, dois dos parâmetros com mais relevância são a tensão limite de cedência e a tensão de rotura.

Os ensaios que cabem nestas designaçס̃es são de enorme importância na caracterização dos polímeros.

4.8 Impacto por queda de dardo - Esta designação envolve vários ensaios, realizados em condiçøes experimentais e com equipamentos diferentes, mas que se destinam sempre a avaliar a energia necessária (resultante da massa do dardo que cai) para provocar a rotura dos provetes da matéria plástica em estudo. Os ensaios podem também permitir estudar a forma e o tipo de rotura, não só pela observação do aspecto da factura, mas também pelo registo de diversos parâmetros obtidos no momento da rotura, quando se utilizam dardos instrumentados (portadores de diversos tipos de sensores), ligados a equipamento de registo e medida).

4.9 Impacto por pêndulo - Esta designação, tal como a anterior, envolve vários ensaios realizados com uma máquina designada por "Pêndulo Universal". Uma massa (martelo), suportado na extremidade de um braço fixo, cai por rotação em torno de um eixo, provocando um impacto sobre um provete. $\mathrm{O}$ que se determina é igualmente a energia necessária para provocar a rotura dos provetes. $\mathrm{O}$ ensaio tem nomes variados consoante a forma e tipo de suporte do provete (p. ex. Charpy e Izod). Os provetes podem ou não ter uma nidentação prévia consoante se pretende determinar a energia de iniciação ou de propagação da fractura. Tal como se referiu no ensaio anterior, para além do valor da energia de rotura, muitas outras conclusð̌es se podem tirar do seu aspecto, bem como do registo de diversos parâmetros obtidos no momento da fractura, quando se utilizam martelos instrumentados (ver 4.9).

4.10 Dureza - Esta designação envolve vários ensaios, na essência de penetração de provetes por diversos tipos de peças (esferas, cones) sujeitas a variadas cargas. Os ensaios efectuam-se a uma temperatura normaliza$\mathrm{da}$, mas próxima da temperatura ambiente $\left(21^{\circ} \mathrm{C}\right)$. Consoante a forma das peças e o procedimento da medida o ensaio toma variados nomes (Vickers, Rockwell, etc.).

4.11 Propagação do rasgamento - A designação cobre variados ensaios realizados sobre filmes produzidos a partir da matéria-prima em estudo. $\mathrm{O}$ mais conhecido é o teste de Elmenderf.

4.12 Propriedades eléctricas - A determinação das propriedades eléctricas dos polímeros é extremamente importante dada a sua extensiva aplicação, não apenas em muito equipamento eléctrico mas também porque p. ex. o PEBD tende a constituir, na prática, o único revestimento de cabos eléctricos. Os ensaios neste campo destinam-se pois a medir as características isolantes dos materiais plásticos. Compreendem, p. ex. a determinação das constantes dielectricas (rigidez dielectrica) e das resistividades volúmica e superficial.

4.13 Microscopia - Referimo-nos, principalmente, ao exame, com o microscópio de transmissão, de finas lamelas do material, obtidas com o microtomo, ou filmes finos, obtidos por prensagem a quente. $\mathrm{O}$ recurso a estas técnicas torna-se obviamente desnecessário quando a amostra se apresenta sob a forma de filme transparente. Este exame, quando em luz natural, permite detectar e/ou identificar defeitos ou inclusð̌es de objectos estranhos, bem como, avaliar p. ex., a uniformidade e concentração dos pigmentos. Quando se utiliza a luz polarizada podem-se aperceber zonas de natureza predominantemente cristalinas ou maior paralelismo das macromoléculas que constituem o polimero.

5. ENSAIOS DE CARACTERIZAÇÃO DE PRODU. TOS ACABADOS - Utilizamos aqui o termo "produtos acabados" para significar peças ou artigos de plástico produzidas pela indústria transformadora.

Nesta categoria podem entrar muitos dos ensaios já referidos em 4. para as matérias-primas plásticas, bem como muitos outros, tanto normalizados como desenvolvidos especificamente para testar determinadas peças. Os tipos de ensaios a seguir referidos não são, igualmente, exclusivos para produtos acabados, sendo frequente a sua realização sobre provetes, tal como os anteriormente descritos.

É muito importante referir a dificuldade de predizer o comportamento dos produtos transformados reais a partir de provetes laboratoriais. Quer isto dizer que, embora se possa prever que uma certa matéria-prima é 
adequada para produzir uma determinada peça, apenas ensaios realizados sobre as peças acabadas permitem comprovar essa predição teórica.

Tais ensaios dividem-se fundamentalmente, em duas categorias.

5.1 Ensaios de curta duração - Na maioria dos casos são ensaios de tracção, impacto, resistência à abrasão e outros que medem fenómenos instantâneos ou de curta duração.

Nesta categoria, para além de ensaios idênticos a muitos dos descritos em 4., cabe uma variedade ilimitada de ensaios imaginados para verificar determinados aspectos específicos do comportamento de cada peça.

5.2 Ensaios de longa duração - Dividem-se fundamentalmente em duas categorias.

5.2.1 Ensaios de fluência - Ensaios em que se registam as deformações provocadas por cargas constantes actuando por períodos de tempo longos.

5.2.2 Ensaios de relaxação - Ensaios em que se registam as forças necessårias para manter determinadas deformaçð̃es previamente exercidas sobre o objecto em apreciação. 